(C) <2020 $>$. This manuscript version is made available under the CC-BY-NC-ND 4.0 license http://creativecommons.org/licenses/by-nc-nd/4.0/

The definitive publisher version is available online at https://doi.org/

10.1016/i.envpol.2020.115456 


\title{
Statistical evaluation of on-road vehicle emissions measurement using a dual remote sensing technique
}

\author{
Yuhan Huang ${ }^{1}$, Yang $\mathrm{Yu}^{1}$, Yat-shing Yam², John L. Zhou ${ }^{1, *}$, Chengwang Lei ${ }^{3}$, \\ Bruce Organ ${ }^{1,4}$, Yuan Zhuang ${ }^{5}$, Wai-chuen Mok $^{1}$, Edward F.C. Chan ${ }^{1,6}$
}

${ }^{1}$ Centre for Green Technology, School of Civil and Environmental Engineering, University of Technology Sydney, NSW 2007, Australia

${ }^{2}$ Environmental Protection Department, Hong Kong Special Administrative Region Government, Hong Kong, China

${ }^{3}$ Centre for Wind, Waves and Water, School of Civil Engineering, The University of Sydney, NSW 2006, Australia

${ }^{4}$ Jockey Club Heavy Vehicle Emissions Testing and Research Centre, Vocational Training Council, Hong Kong, China

${ }^{5}$ School of Automotive and Transportation Engineering, Hefei University of Technology, Hefei, China

${ }^{6}$ Faculty of Science and Technology, Technological and Higher Education Institute of Hong Kong, Hong Kong, China

Corresponding author:

Prof John L. Zhou; Email: junliang.zhou@ uts.edu.au; Phone: +61-2-95142023

Please cite this article as:

Y. Huang, Y. Yu, Y.S. Yam, J.L. Zhou, C. Lei, B. Organ, Y. Zhuang, W.C. Mok, E.F.C. Chan, Statistical evaluation of on-road vehicle emissions measurement using a dual remote sensing technique. Environmental Pollution 2020; 267: 115456. https://doi.org/10.1016/j.envpol.2020.115456 


\begin{abstract}
On-road remote sensing (RS) is a rapid, non-intrusive and economical tool to monitor and control the emissions of in-use vehicles, and currently is gaining popularity globally. However, a majority of studies used a single RS technique, which may bias the measurements since RS only captures a snapshot of vehicle emissions. This study aimed to use a unique dual RS technique to assess the characteristics of on-road vehicle emissions. The results show that instantaneous vehicle emissions are highly dynamic under real-world driving conditions. The two emission factors measured by the dual RS technique show little correlation, even under the same driving condition. This indicates that using the single RS technique may be insufficient to accurately represent the emission level of a vehicle based on one measurement. To increase the accuracy of identifying high-emitting vehicles, using the dual RS technique is essential. Despite little correlation, the dual RS technique measures the same average emission factors as the single RS technique does when a large number of measurements are available. Statistical analysis shows that both RS systems demonstrate the same Gamma distribution with $\geq 200$ measurements, leading to converged mean emission factors for a given vehicle group. These findings point to the need for a minimum sample size of $200 \mathrm{RS}$ measurements in order to generate reliable emission factors for on-road vehicles. In summary, this study suggests that using the single or dual RS technique will depend on the purpose of applications. Both techniques have the same accuracy in calculating average emission factors when sufficient measurements are available, while the dual RS technique is more accurate in identifying high-emitters based on one measurement only.
\end{abstract}

Keywords: Dual scope technique; Emission factors; Emission variability; On-road remote sensing; Real driving emissions 


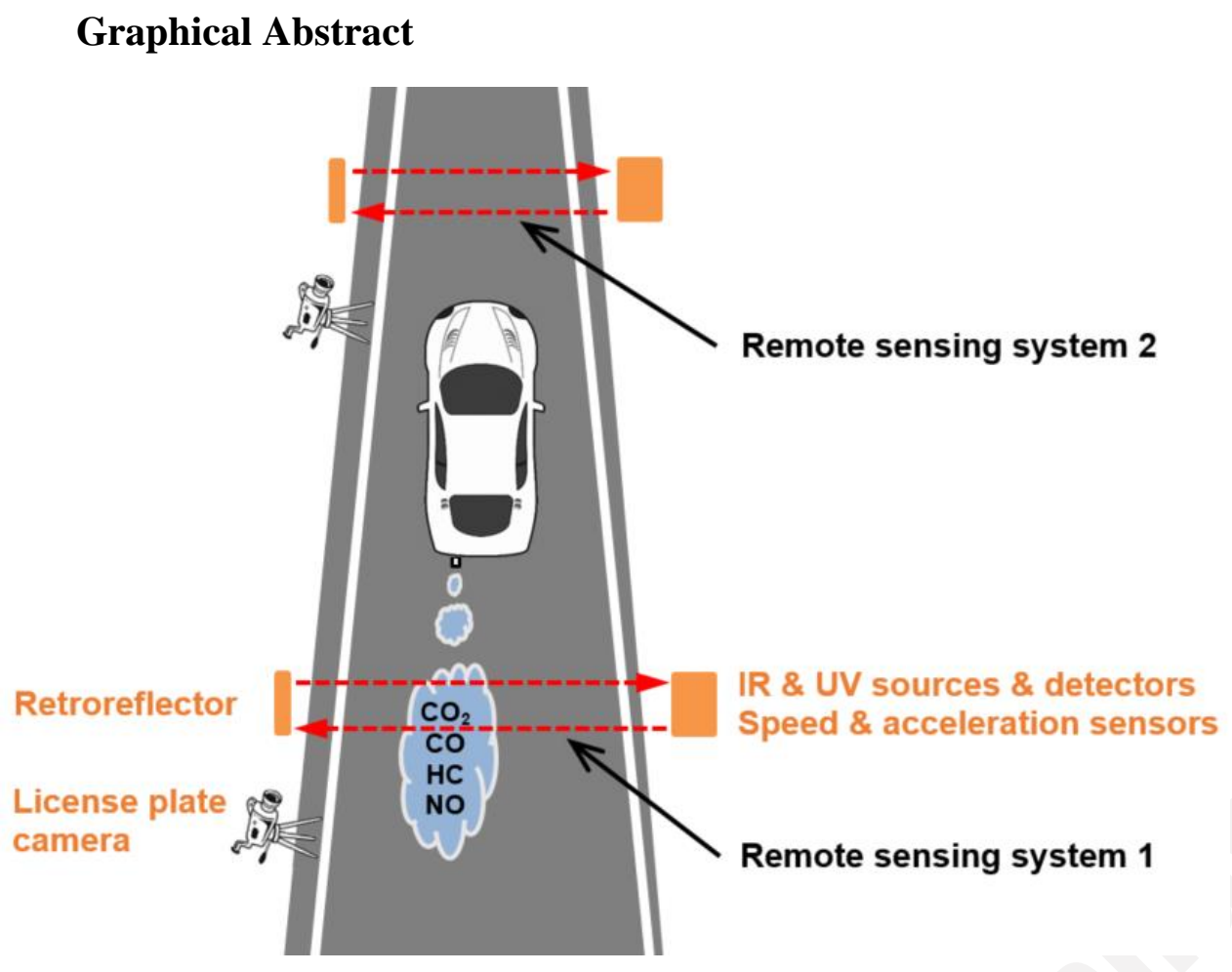

\section{Highlights}

- A unique dual RS technique is used to measure on-road vehicle emissions.

- Instantaneous vehicle emissions are highly dynamic under real driving conditions.

- The two emission factors measured by dual RS technique show little correlation.

- Emission factors converge to a Gamma distribution with over 200 RS measurements.

- Dual RS technique is recommended for accurate identification of high-emitting vehicles. 


\section{Introduction}

Ambient air pollution poses a major threat to human health, causing over four million deaths yearly due to chronic respiratory diseases, lung cancer, stroke and heart disease (WHO, 2020). There is no safe level of air pollution as even exposure to low-level air pollution (such as those seen in Australia and Japan) increases the risk of illness and mortality (Hanigan et al., 2019; Zhao et al., 2020). The road transport sector, in particular diesel vehicles, is a main source of air pollution in many cities worldwide, such as Sydney and Hong Kong (Anenberg et al., 2017; Huang et al., 2020b). For example, the latest Air Emissions Inventory in New South Wales (NSW), the most populous state in Australia, reported that on-road motor vehicles alone contributed $43.4 \%, 55.4 \%, 11.9 \%$ and $12.9 \%$ of the total anthropogenic emissions of $\mathrm{CO}, \mathrm{NO}_{\mathrm{x}}, \mathrm{PM}_{10}$ and $\mathrm{PM}_{2.5}$, respectively in Sydney in 2013 (NSW EPA, 2019).

Significant effort has been undertaken to curb vehicle emissions, such as more stringent automotive emission standards, new engine and vehicle technologies, better fuel quality and renewable fuels (He $e t$ al., 2017; Huang et al., 2018a). However, the current effort mostly concerns new vehicles but lacks control on in-use vehicles. Although new vehicles are manufactured to meet emission regulations, their in-use performance may not achieve the same standards due to deterioration, improper maintenance, tampering or failure of the engine components. Recent studies showed that some common faults in the engine combustion and exhaust after-treatment systems could lead to much higher emissions than the standard limits (Huang et al., 2019a; Organ et al., 2020). Therefore, it is of the same importance to control in-use vehicle emissions as to introduce stringent emission standards for new vehicles. On-road remote sensing (RS) technology is developed for this purpose. It emits infrared (IR) and ultraviolet (UV) beams at a typical tailpipe height across a single lane road and measures the vehicle emissions via light attenuation through the exhaust plume when a vehicle passes by, causing little interference to driving. The on-road RS technology is a rapid, non-intrusive and economical tool for the monitoring and control of in-use vehicle emissions, which has gained significant attention recently.

Bishop and Haugen (2018) analysed a large RS dataset collected in Chicago during 1989 to 2016. Sharp reductions of emission factors ( $\mathrm{g} / \mathrm{kg}$ fuel) of light-duty vehicles were observed, with $\mathrm{CO}$ reduced by one order of magnitude since 1989, HC by a factor of >20 since 1989 and NO by 79\% since 1997 . Organ et al. (2019) evaluated the effectiveness of a high-emitter enforcement program for gasoline and liquefied petroleum gas (LPG) vehicles using RS technology in Hong Kong. They found significant overall reductions of $55.9 \%$ for HC, 50.5\% for CO and 60.9\% for NO during 2012 to 2016. Pujadas et al. (2017) assessed the emissions performance of passenger cars in Madrid using RS. They found that $\mathrm{NO} / \mathrm{CO}_{2}$ of diesel vehicles did not reduce with the introduction of increasingly stringent emission standards and this trend differed greatly among various brands and engine models. Huang et al. (2018c) further investigated the emission trends of the dominant diesel vehicle models in Hong Kong. They observed a significant increase of $\mathrm{NO}$ emissions ( $\mathrm{g} / \mathrm{kg}$ fuel) from one dominant model during 2005 to 2011 , which was caused by the change of fuel supply system from indirect to direct fuel injection. The above studies observed opposite NO emission trends due to the different fuel types concerned, i.e. gasoline and LPG vehicles in Bishop and Haugen (2018); Organ et al. (2019) vs diesel vehicles in Huang et al. (2018c); Pujadas et al. (2017). RS studies showed that gasoline $\mathrm{NO}_{\mathrm{x}}$ reduced obviously in the past 15-20 years but diesel $\mathrm{NO}_{\mathrm{x}}$ did not reduce over the same period including those vehicles equipped with 
exhaust after-treatment systems for $\mathrm{NO}_{\mathrm{x}}$ control (Carslaw and Rhys-Tyler, 2013; Chen and BorkenKleefeld, 2014). Current RS studies mostly used a horizontal configuration and new RS systems are being developed. Ropkins et al. (2017) evaluated the performance of a novel facing-down RS system by using a simulated exhaust gas, a portable emission measurement system (PEMS) and a car chaser. The experimental results showed high sensitivity and linearity of the facing-down configuration over a wide range of vehicle speeds.

One main challenge in RS measurements is that the instantaneous tailpipe emissions are highly dynamic under real-world driving conditions, while RS can only capture a snapshot of emissions when the vehicle passes by a RS measurement site. A recent PEMS study on a Euro 6 diesel vehicle showed that high instantaneous $\mathrm{NO}_{\mathrm{x}}$ events represented a large proportion of the total $\mathrm{NO}_{\mathrm{x}}$ although they only accounted for a small proportion of the driving time (Mera et al., 2019). Transient chassis dynamometer tests showed that the probability of extreme $\mathrm{NO} / \mathrm{CO}_{2}$ high-emitting event was generally evenly distributed over different driving conditions (Huang et al., 2019b). Despite the large variations of instantaneous emissions, all existing studies only analysed the emissions data of one RS system, except for one early study which used two remote sensors to screen gross polluters for an immediate on-road Smog Check (Beaton et al., 1995). There is a lack of investigation on how representative the snapshot RS measurements are for evaluating the mean emission factors and their trends, although the existing RS studies usually used a large number of measurements and it was believed that the random variations were cancelled out when they were averaged (Austin et al., 2004).

The key innovation of this study is the use of a unique dual RS technique which deploys two RS systems in tandem at any measurement site. The characteristics of a pair of emission factors measured consecutively are investigated on the basis of a large sample size, i.e. 405096 valid pairs of emission measurements of gasoline, LPG and diesel vehicles. The mean emission factors and trends derived from the dual RS technique are evaluated against the conventional single RS technique. Further, statistical analysis is conducted to determine the minimum sample size required for deriving converged results, which provides a valuable guide for the accurate and effective use of the RS technology.

\section{Methodology}

\subsection{Dual RS technique}

The RS systems ETC-S420 were provided by the Environmental Technology Ltd. Co. based on the requirements from the Hong Kong Environmental Protection Department (HKEPD). The measurement uncertainties of ETC-S420 are about $\pm 15 \%$. HKEPD (2020b) has successfully used it to screen gasoline and LPG high-emitters for emission enforcement from 1 September 2014. To set up a dual RS station, two units of ETC-S420 RS systems (denoted by RSS1 and RSS2) were placed with a separation distance of one second under the average driving speed of the measurement site. The exact separation distance ranged between 3 and $20 \mathrm{~m}$, depending on the site characteristics. A site with a higher average driving speed had a longer separation distance. Choosing one second separate distance was to ensure that the dual RS technique could measure two different engine conditions. The passing vehicle is very likely a persistent high-emitter if both RS readings are high, which is the basis of the dual RS technique. The setup of a dual RS measurement site is illustrated in Fig. 1. In each RS system, there are beam sources 
and detectors, a retroreflector, speed and acceleration sensors and a license plate camera. Measurements are triggered when the beams are blocked by a passing vehicle, including the emissions of $\mathrm{CO}, \mathrm{CO}_{2}$, $\mathrm{HC}$ and NO, the driving conditions of speed and acceleration, and the licence plate number. The license plate number is used to acquire the vehicle's registration information, such as its make, model, manufacture year, and fuel type. The exhaust emissions after a vehicle are affected by a number of factors such as vehicle speed, engine conditions, wind speed and wind direction. Therefore, remote sensing is unable to measure the absolute emission concentrations. Instead, remote sensing can only measure the relative emission ratios of $\mathrm{CO} / \mathrm{CO}_{2}, \mathrm{HC} / \mathrm{CO}_{2}$ and $\mathrm{NO} / \mathrm{CO}_{2}$ which are assumed to be constant for a given plume in the near wake region after the vehicle tailpipe exit (Bishop et al., 1989; Burgard et al., 2006; Huang et al., 2020a). For this reason, meteorological conditions are not measured in remote sensing but are taken into account before proceeding with measurements. These emission ratios can be used to evaluate the performance of a vehicle, such as for calculating the fuel mass-based emission factors.

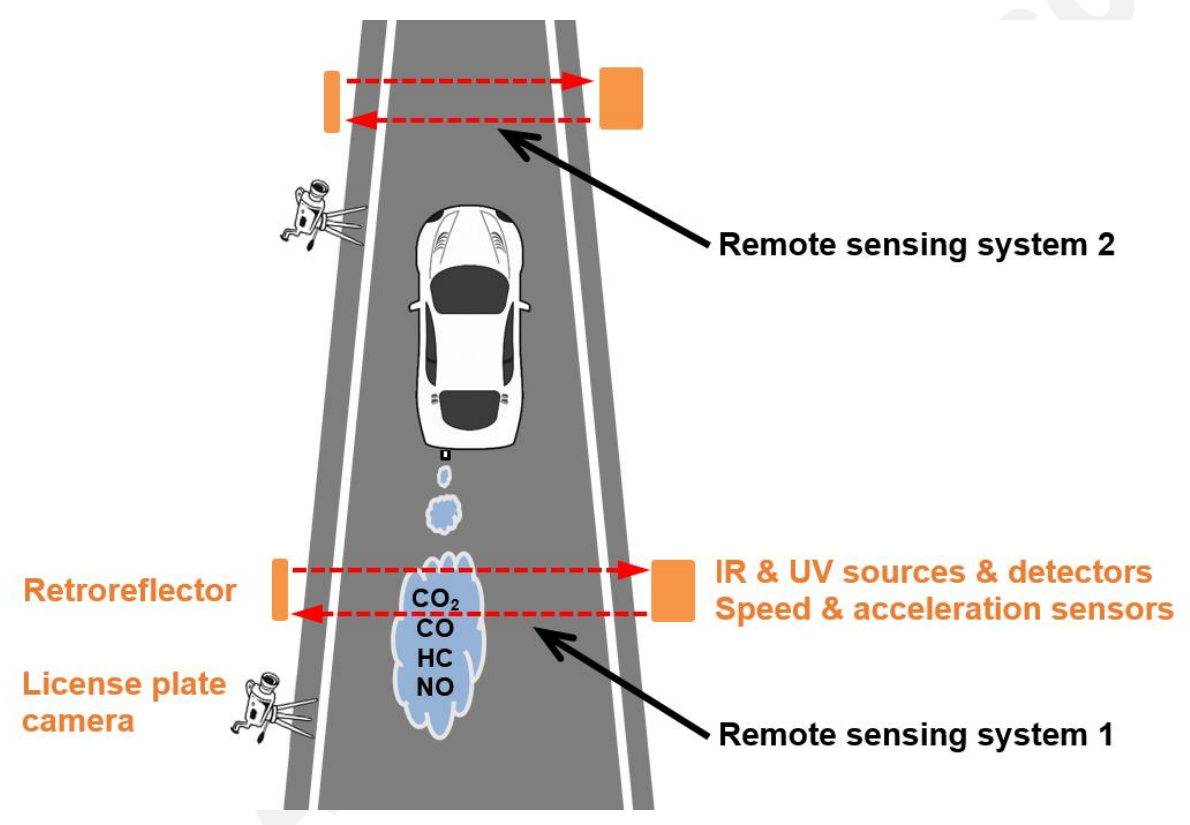

Fig. 1. Setup of a dual RS measurement site.

\subsection{Data collection and treatment}

In the present study, vehicle emissions were measured at 92 sites (Fig. S1, Supplementary Information) across the Hong Kong city from 2 January to 31 December 2018. Measurement sites are usually at highway on-ramps so that they are single-lane roads with slight uphill gradients. This is to ensure that vehicle engines are under load to produce sufficient exhaust gas for measurement. In addition, the sites are not close to traffic lights or intersections so that off-cycle emissions due to sharp acceleration/deceleration can be avoided. The sites also have a busy but not congested traffic to collect sufficient emissions data. At the beginning of each measurement day, both RS systems were calibrated using a puff of a reference span gas with known pollutant concentrations to ensure that they were working within the accuracy specifications (i.e. $\pm 15 \%$ ). In addition, in-field calibrations were carried out every $2 \mathrm{~h}$ during the measurement day. The data collected in the previous $2 \mathrm{~h}$ were omitted if either 
RS system failed the field calibration, due to the high accuracy requirements of a legislative enforcement program. Therefore, both RS systems correlated well in the calibration checks.

The one-year continuous measurement program collected 930433 and 932991 emission records by RSS1 and RSS2, respectively. RSS1 was set up at upstream of the traffic direction so that it measured vehicles approaching the measurement site, while RSS2 was at downstream measuring data when vehicles departed from the site. A Matlab code (version R2018b) was used to pair the two datasets by using the vehicle license plate number (unique to each vehicle) and the measurement time (time difference within a few seconds). The Matlab code matched a total number of 904684 pairs of emission records. One pair of emission records were considered valid only when both RS systems measured sufficient $\mathrm{CO}_{2}$ exhaust plumes for determining the emission ratios of $\mathrm{CO} / \mathrm{CO}_{2}, \mathrm{HC} / \mathrm{CO}_{2}$ and $\mathrm{NO} / \mathrm{CO}_{2}$ (Carslaw et al., 2011; Chen and Borken-Kleefeld, 2014, 2016; Huang et al., 2018c). In addition, the driving conditions when passing by both RS systems were matched with the Hong Kong Transient Emission Testing (HKTET) cycle (i.e. $<90 \mathrm{~km} / \mathrm{h}$ for speed and -5 to $3 \mathrm{~km} / \mathrm{h} / \mathrm{s}$ for acceleration) which is the laboratory test for emission compliance check of in-use vehicles in Hong Kong (Huang et al., 2019b). By applying the above two criteria, 405096 pairs of valid emission records were selected. Equations (1-3) were applied to calculate the fuel mass based emission factors (EF) (Burgard et al., 2006; Huang et al., 2018b).

$$
\begin{aligned}
& E F_{C O}=\frac{28}{0.014} \times \frac{\mathrm{CO}_{\mathrm{CO}_{2}}}{1+\mathrm{CO}_{\mathrm{CO}}+6 \mathrm{HC} / \mathrm{CO}_{2}}[\mathrm{~g} / \mathrm{kg} \text { fuel }] \\
& E F_{H C}=\frac{2 \times 44}{0.014} \times \frac{\mathrm{HC}_{\mathrm{CO}}}{1+\mathrm{CO}_{2} \mathrm{CO}_{2}+6 \mathrm{HC} / \mathrm{CO}_{2}}[\mathrm{~g} / \mathrm{kg} \text { fuel }] \\
& E F_{N O}=\frac{30}{0.014} \times \frac{\mathrm{NO} / \mathrm{CO}_{2}}{1+{\mathrm{CO} / C O_{2}+6 \mathrm{HC} / \mathrm{CO}_{2}}_{[}}[\mathrm{g} / \mathrm{kg} \text { fuel }]
\end{aligned}
$$

\subsection{Sample characteristics}

The characteristics of the valid emission dataset are given in Table 1. The dataset includes a total of 405096 pairs of emission records for 182183 unique vehicles, including 125848, 37487 and 18848 unique gasoline, diesel and LPG vehicles, respectively. LPG vehicles are measured more frequently (5.9 times per vehicle) than gasoline (1.6) and diesel (2.4) vehicles because LPG vehicles are used for public transport in Hong Kong which are used extensively. The average model year of diesel vehicles (2012.0) is obviously newer than that of gasoline (2010.4) and LPG (2010.2) vehicles. This is mainly because older (pre-Euro IV) commercial diesel vehicles are being progressively removed from roads by a subsidised mandatory phasing-out program from 1 Mar 2014 to 30 Jun 2020 (HKEPD, 2020a). Table 1 also shows that the average engine size $(4231 \mathrm{cc})$ of diesel vehicles are larger than those of gasoline (2343 cc) and LPG (2182 cc) vehicles. This is because diesel vehicles are widely used for heavy duty applications such as goods vehicles and buses. Table 2 shows the driving conditions of the sampled vehicles when passing by RSS1 and RSS2. As shown in Table 2, most of the vehicles (97.2\%) passed by the two RS systems within 1 or 2 seconds. Only a small number of vehicles $(2.7 \%)$ passed by RS sites slowly due to either high traffic volumes or drivers deliberately driving slowly to avoid the excessive emissions of their vehicles to be detected by the gasoline and LPG high-emitters enforcement program. This can be seen in the averaged deceleration at RSS1 in Table 2. 
Table 1. Characteristics of the sampled fleet.

\begin{tabular}{llllll}
\hline $\begin{array}{l}\text { Engine } \\
\text { type }\end{array}$ & $\begin{array}{l}\text { No. of valid No. of unique } \\
\text { pairs (A) }\end{array}$ & $\begin{array}{l}\text { Average measurements } \\
\text { vehicles (B) }\end{array}$ & $\begin{array}{l}\text { Average } \\
\text { model year }\end{array}$ & $\begin{array}{l}\text { Average engine } \\
\text { size (cc) }\end{array}$ \\
\hline Gasoline & 204193 & 125848 & 1.6 & 2010.4 & 2343 \\
Diesel & 90127 & 37487 & 2.4 & 2012.0 & 4231 \\
LPG & 110776 & 18848 & 5.9 & 2010.2 & 2182 \\
Total & 405096 & 182183 & 2.2 & 2010.7 & 2719 \\
\hline
\end{tabular}

Table 2. Driving conditions of the sampled fleet.

\begin{tabular}{|c|c|c|c|c|c|c|}
\hline $\begin{array}{l}\text { Time interval } \\
\text { between } \\
\text { RSS1 and } \\
\text { RSS2 (s) }\end{array}$ & $\begin{array}{l}\text { No. of } \\
\text { valid pairs }\end{array}$ & Percentage & $\begin{array}{l}\text { RSS1 average } \\
\text { speed }(\mathrm{km} / \mathrm{h})\end{array}$ & $\begin{array}{l}\text { RSS1 average } \\
\text { acceleration } \\
(\mathrm{km} / \mathrm{h} / \mathrm{s})\end{array}$ & $\begin{array}{l}\text { RSS2 average } \\
\text { speed }(\mathrm{km} / \mathrm{h})\end{array}$ & $\begin{array}{l}\text { RSS2 average } \\
\text { acceleration } \\
(\mathrm{km} / \mathrm{h} / \mathrm{s})\end{array}$ \\
\hline 1 & 288594 & $71.2 \%$ & 40 & 0.2 & 40 & 0.1 \\
\hline 2 & 105451 & $26.0 \%$ & 30 & 0.1 & 30 & 0.2 \\
\hline 3 & 8664 & $2.1 \%$ & 17 & -0.1 & 18 & 0.3 \\
\hline 4 & 1544 & $0.4 \%$ & 13 & -0.2 & 12 & 0.2 \\
\hline$\geq 5$ & 843 & $0.2 \%$ & 12 & -0.4 & 11 & 0.3 \\
\hline
\end{tabular}

\section{Results and discussion}

\subsection{Characteristics of instantaneous vehicle emissions}

With the dual RS technique, the emissions of one vehicle will be measured twice consecutively within 1-2 seconds when passing by a measurement site. Fig. 2 plots the CO (a), HC (b) and NO (c) emission factors measured by RSS1 against those measured by RSS2. Generally, the correlations between RSS1 and RSS2 measurements are relatively weak, with $\mathrm{R}^{2}$ values of $0.43,0.13$ and 0.52 for $\mathrm{CO}, \mathrm{HC}$ and NO, respectively. In particular, HC and NO emissions measured by RSS1 and RSS2 are relatively independent, as shown in Figs. $\mathbf{2 b}$ and 2c. For CO emissions, however, Fig. 2a shows that both measurements tend to have similar high emission levels when both RSS1 and RSS2 readings are high (e.g. $>200 \mathrm{~g} / \mathrm{kg}$ fuel, as highlighted in the dashed box). The mean manufacture year is 2005.6 for the measurements in the box, which is much older in comparison to the mean manufacture year (2010.7) of the whole dataset. This indicates that the extreme $\mathrm{CO}$ emissions are from either pre three-way catalyst (TWC) vehicles or vehicles with open loop control engines, both with less engine variabilities. Nevertheless, the correlation between RSS1 and RSS2 is still weak even when both measurements are above $200 \mathrm{~g} / \mathrm{kg}$ fuel, with an $\mathrm{R}^{2}$ value of 0.56 (Fig. S2). 

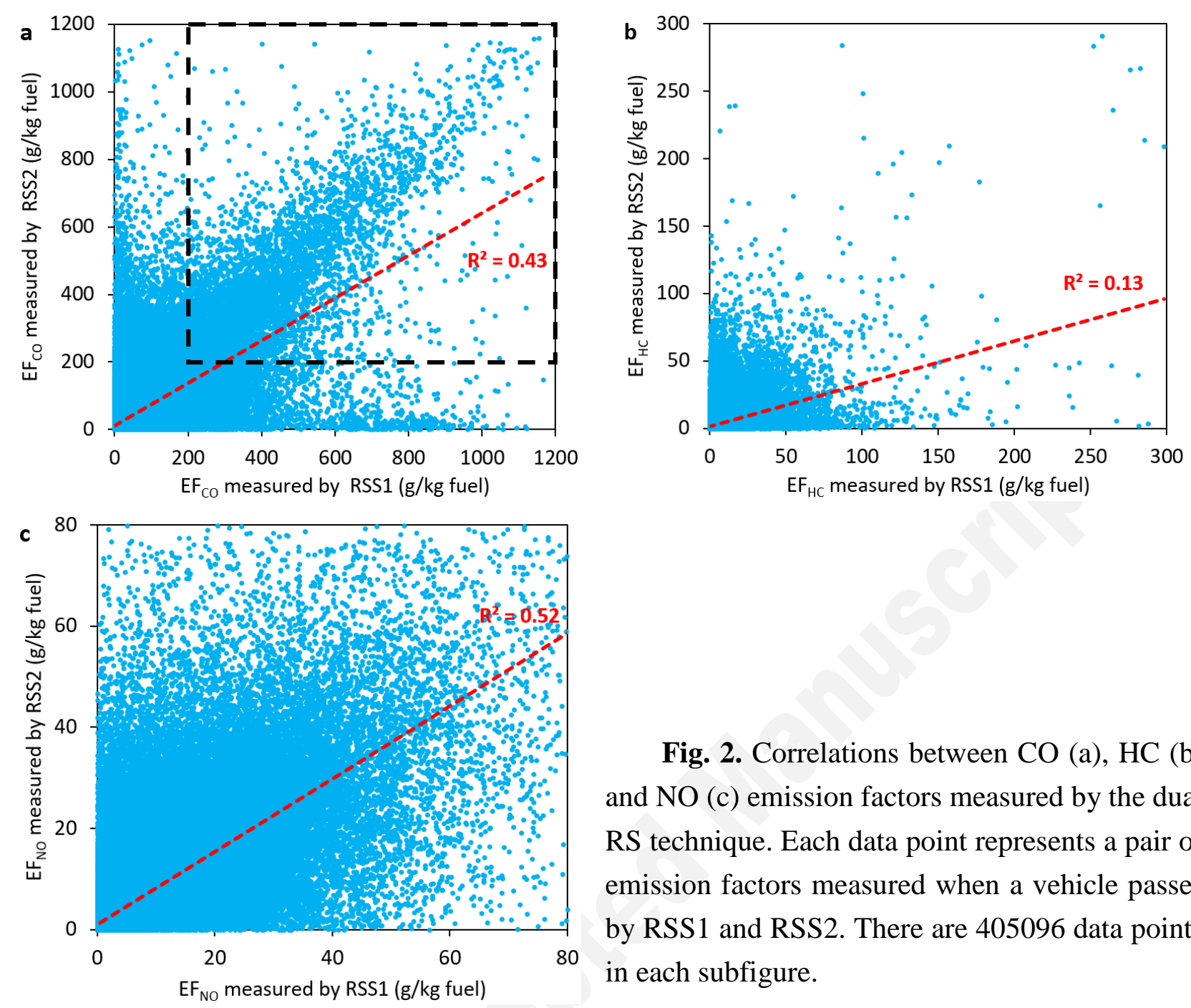

Fig. 2. Correlations between $\mathrm{CO}(\mathrm{a}), \mathrm{HC}(\mathrm{b})$ and NO (c) emission factors measured by the dual RS technique. Each data point represents a pair of emission factors measured when a vehicle passes by RSS1 and RSS2. There are 405096 data points in each subfigure.

Refining the comparison by fuel types or driving conditions does not improve the correlations between the emission factors measured by RSS1 and RSS2. Table 3 shows the derived $\mathrm{R}^{2}$ values after refining the comparison by fuel types (i.e. gasoline, diesel and LPG vehicles) and driving conditions. In the refinement of driving conditions, only the emissions measured from vehicles having the same driving conditions when they pass by RSS1 and RSS2 are used. Three typical driving conditions of cruising $(0 \mathrm{~km} / \mathrm{h} / \mathrm{s})$, accelerating $(2 \mathrm{~km} / \mathrm{h} / \mathrm{s})$ and decelerating $(-2 \mathrm{~km} / \mathrm{h} / \mathrm{s})$ at $40 \mathrm{~km} / \mathrm{h}$ (which is the average driving speed, Table 2) are investigated. As shown in Table 3, the correlations between RSS1 and RSS2 are still relatively weak even for the same fuel type vehicles or under the same driving conditions. This further indicates that the instantaneous vehicle emissions are highly dynamic under real-world driving. The instantaneous vehicle emissions are mainly determined by the engine combustion conditions and can be relatively stable when all engine operating conditions are constant, such as in a steady-state engine dynamometer testing which controls the engine speed, load, intake air flow, fuel injection and ignition. However, when it comes to real-world driving, the only measured (controlled) parameters are the driving speed and acceleration. The engine may be under different operation conditions although the driving speed and acceleration are the same, leading to different instantaneous tailpipe emissions. PEMS tests showed that the emission concentrations are highly variable even when the vehicle is driven under similar conditions (Huang et al., 2019c; Mendoza- 
Villafuerte et al., 2017). It should be noted that such high variability is not due to the testing methods, but due to the vehicles themselves (Bishop et al., 1996). It is also worth mentioning that the RS measurement sites are chosen at highway on-ramps with slight uphill grades. As a result, the vehicle engines tend to be under load, which may lead to higher emission variabilities and thus lower correlations. Nevertheless, Table 3 shows that the correlation is still small even when the driving condition is unchanged.

Table 3. $\mathrm{R}^{2}$ values of emission factors measured by RSS1 versus RSS2.

\begin{tabular}{llll}
\hline Sub-dataset $*$ & CO & HC & NO \\
\hline All data (405096) & 0.43 & 0.13 & 0.52 \\
Gasoline (204193) & 0.30 & 0.04 & 0.35 \\
Diesel (90127) & 0.12 & 0.02 & 0.43 \\
LPG (110776) & 0.54 & 0.22 & 0.51 \\
Cruising (3831) & 0.25 & 0.06 & 0.54 \\
Accelerating (181) & 0.63 & 0.54 & 0.52 \\
Decelerating (33) & 0.15 & 0.12 & 0.25 \\
\hline
\end{tabular}

* Numbers in the parentheses are the numbers of data points for the plots.

\subsection{Effect of sample size on emissions distribution}

RS can measure the emissions of a large number of vehicles over a short time, which are widely used to examine the emission trends as a result of various factors, such as more stringent vehicle emission standards (Carslaw et al., 2011; Chen and Borken-Kleefeld, 2014; Lau et al., 2012; Pujadas et al., 2017), engine technology advancement (Huang et al., 2018c; Sjödin, 1994), engine deterioration (Borken-Kleefeld and Chen, 2015; Chen and Borken-Kleefeld, 2016) and other vehicle emission control programs such as fleet renewal and inspection and maintenance (I/M) programs (Bishop et al., 2013; Bishop et al., 2012; Organ et al., 2019; Stedman et al., 1997). These studies all used only one set of RS system. However, section 3.1 shows that the instantaneous emissions of one vehicle are highly dynamic. Therefore, a key question is if this would bias the emission trends derived from snapshot measurements. Fig. 3 compares the variations of mean emission factors with manufacture year measured by the single and dual RS techniques. In the single RS technique, the emission level of a vehicle is indicated by the first RS system only (i.e. RSS1). In the dual RS technique, the emission level of a vehicle is indicated by the average of two consecutive measurements by the first and second RS systems (i.e. RSS1 and RSS2). As shown in Fig. 3, the emission trends are generally the same for both techniques, in particular for vehicles manufactured in or after 2000. There are slight differences in the emission factors of vehicles manufactured before 2000 due to their relatively small sample sizes ( $<1000$ emission records per data point). Small sample sizes also result in large uncertainties in the mean emission factors, as evidenced by the large error bars. 

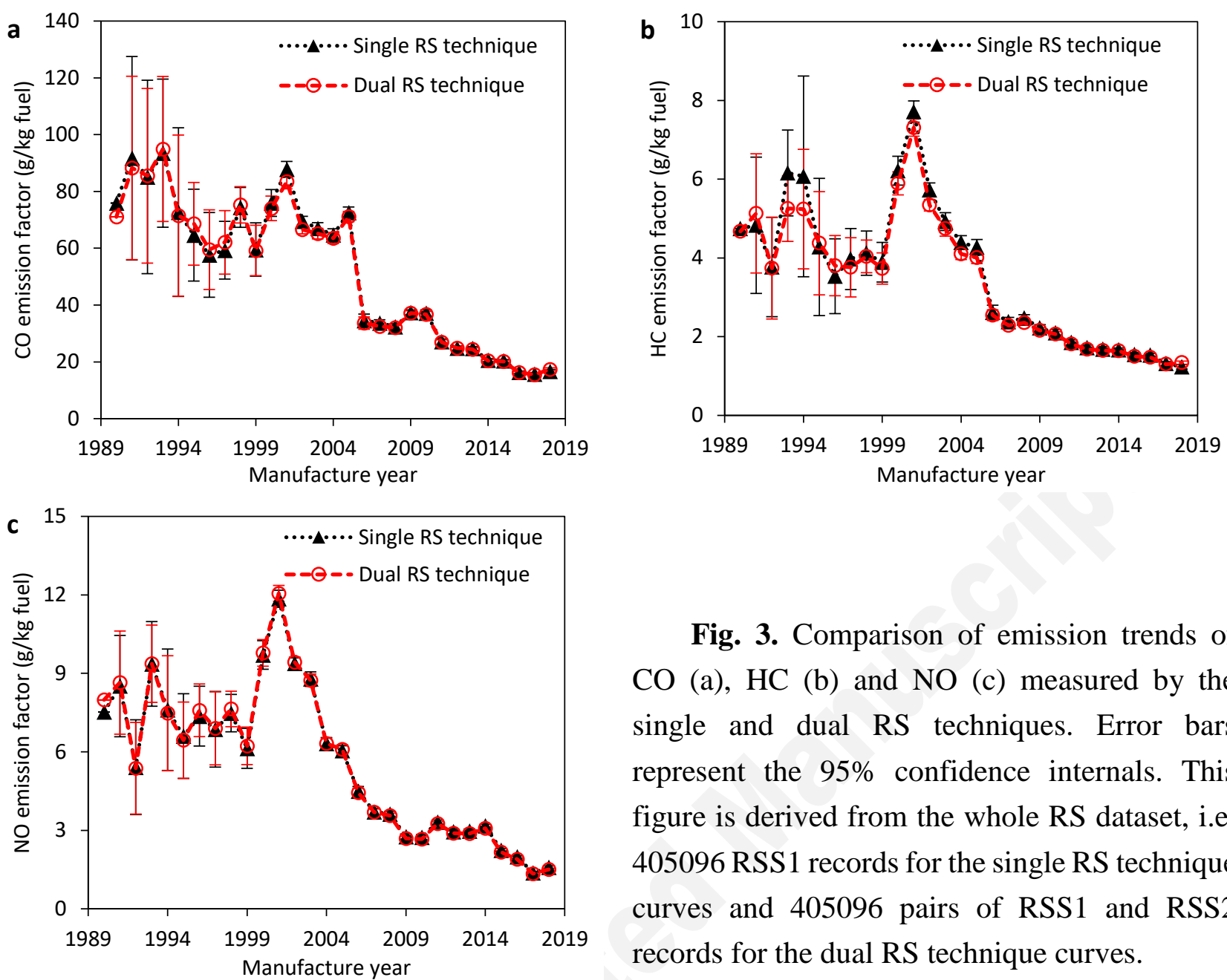

Fig. 3. Comparison of emission trends of $\mathrm{CO}$ (a), HC (b) and NO (c) measured by the single and dual RS techniques. Error bars represent the $95 \%$ confidence internals. This figure is derived from the whole RS dataset, i.e. 405096 RSS1 records for the single RS technique curves and 405096 pairs of RSS1 and RSS2 records for the dual RS technique curves.

Although instantaneous vehicle emissions are highly dynamic, the results in Fig. 3 illustrate that dual RS technique will generate the same mean emission factors and trends as the traditional single RS technique does when a large number of measurements are available (e.g. 405096 in this study). However, in previous RS studies, the datasets varied in a large range from a few thousand measurements (Baum et al., 2001; Stephens and Cadle, 1991) to over three million measurements (Bishop et al., 2000). As a result, the number of measurements used to calculate the mean emission factors in each manufacture year ranged from less than 100 to over 10000. Since RS only measures instantaneous vehicle emissions within a half second, it is required to collect a sufficient number of measurements to generate reliable and converged mean emission factors. Accordingly, a key question is how big a sample size is considered sufficient. To answer this question, a Matlab code is used to randomly select a certain number of pairs of emission factors from the whole dataset. Fig. 4 depicts the distributions of NO emission factors of the randomly selected sub-datasets with difference sample sizes. The distributions of CO and HC are shown in Figs. S3 and S4, respectively. No statistical distribution can be observed for either RSS1 or RSS2 sub-dataset when the sample size is very small (e.g. 10). As the sample size increases, both the randomly selected sub-datasets converge to the same distribution, which is highly skewed towards the lower emission side. Such a skewed distribution can be well fitted with a Gamma distribution curve $\Gamma(k, \theta)$ (Zhang et al., 1994), the shape parameter (k) and scale parameter $(\theta)$ of which are shown in the individual subfigures. 

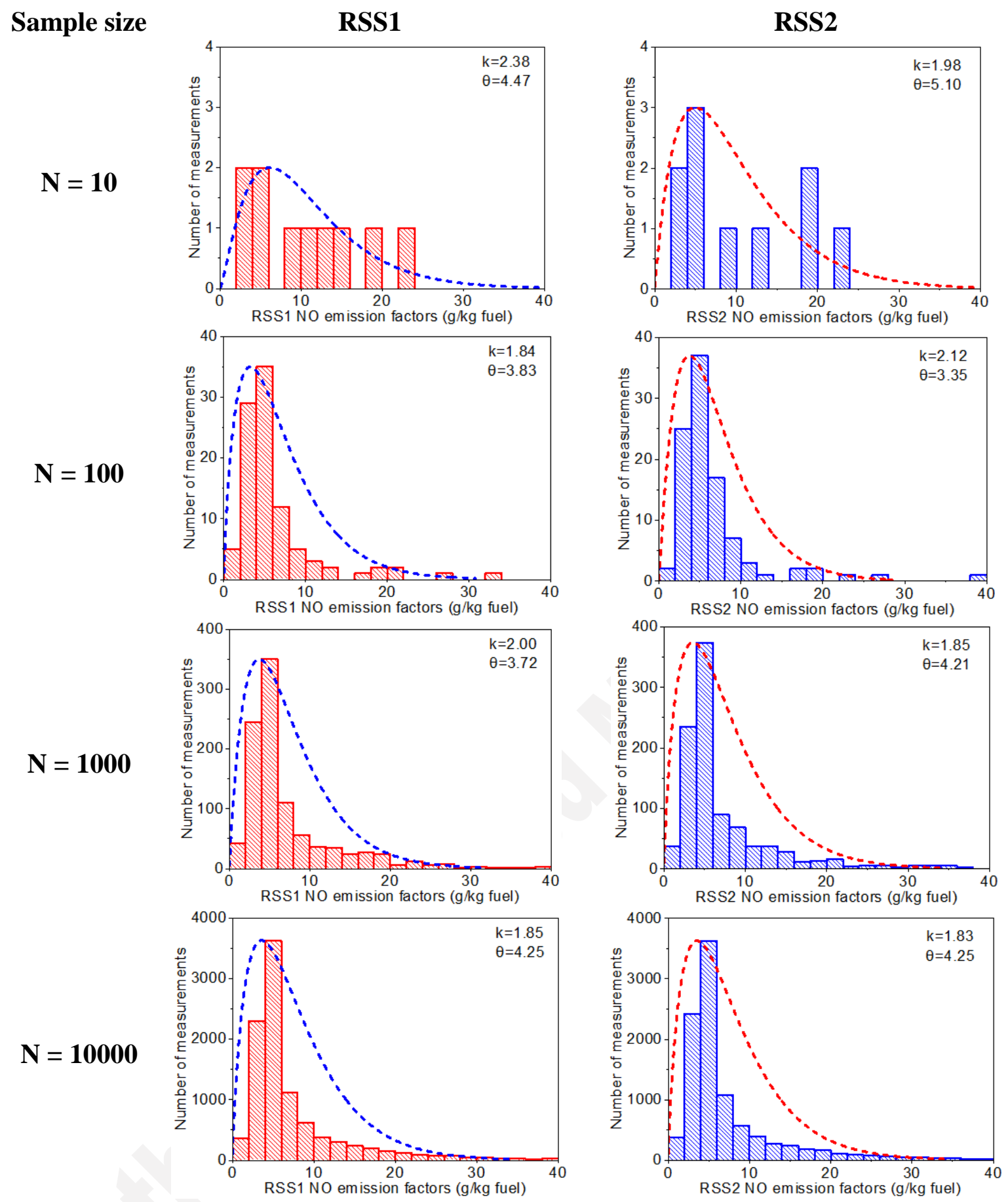

Fig. 4. Distributions of NO emission factors of the randomly selected sub-datasets from RSS1 and RSS2 measurements. Gamma distribution curves are used to fit the histograms.

Since each randomly selected sub-dataset may show a different distribution, the Matlab code has been run repeatedly to obtain 100 random sub-datasets for a given sample size to quantitatively evaluate the effect of sample size on the convergence of emission distribution. The Gamma distribution curve is used to fit the histograms of the sub-datasets. The maximum likelihood estimates (MLEs) algorithm is used to calculate the two parameters. Fig. 5 shows the mean shape and scale parameters of the 100 subdatasets for NO emission factors. Generally, both RSS1 and RSS2 sub-datasets have very similar parameters for a given sample size. For the shape parameter, it reduces quickly from 3.07/2.96 to 2.11/2.09 when the sample size increases from 10 to 50 for RSS1/RSS2. It then reduces slowly to 
1.90/1.92 at sample size of 200 and finally becomes constant when the sample size is over 200. For the scale parameter, it fluctuates when the sample size is smaller than 200 and then approaches a constant value with further increase of the sample size. In addition, both the shape and scale parameters vary significantly (indicated by the large error bars) among the random selections when the sample size is smaller than 200. The uncertainties become relatively small (indicated by the small error bars) when the sample size is over 200. Fig. 5 also shows that there are slight differences in the converged scale parameters between RSS1 and RSS2. This is because the distributions of RSS1 and RSS2 datasets are not exactly identical. The shape and scale parameters of the whole dataset (i.e. sample size of 405096) are 1.86 and 4.20 for RSS1, and 1.88 and 4.12 for RSS2, respectively. However, such small differences in the shape and scale parameters result in negligible difference between the two Gamma curves, as shown in Fig. S5. The results in Fig. 5 indicate that a minimum sample size of 200 RS measurements is required to obtain a converged emission distribution, and in turn to get an accurate mean emission factor. The Gamma shape and scale parameters of CO and HC emissions factors are shown in Figs. S6 and S7, respectively, which demonstrate similar variations and indicate the same minimum sample size of 200 for converged emission distributions. This study agrees well with an earlier study by Chen et al. (2019), who used Monte Carlo simulations to investigate the effect of sample size on emission mean and variance and reported that no more than $200 \mathrm{RS}$ records were sufficient to approximate the mean NO emissions of Euro 4-6 diesel cars. Our study further demonstrates that the 200 minimum sample size also applies to other emission species (i.e. HC and CO) and fuel types (i.e. gasoline and LPG vehicles). 200 may be a conservative estimate, considering that the vehicle engines tend to be under load due to the slight uphill grades of RS sites which may lead to larger emission variabilities. However, RS sites require uphill grades to produce sufficient exhaust gas for valid measurements. Therefore, 200 is deemed a suitable estimate for RS applications.

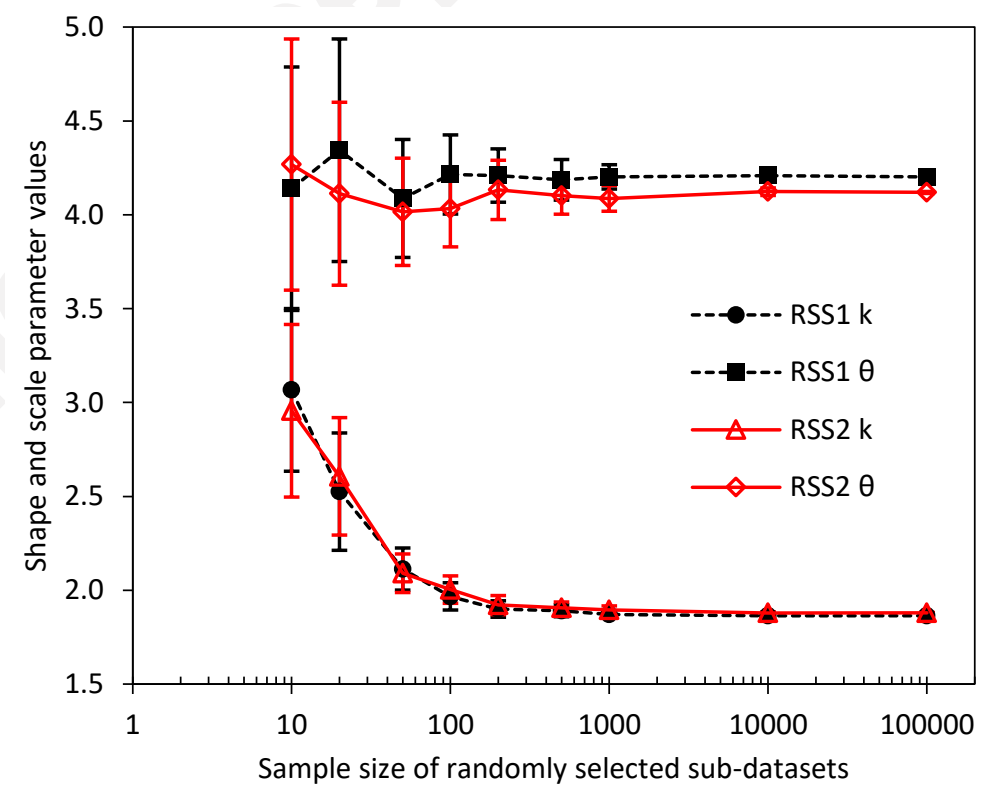

Fig. 5. Average shape and scale parameters of 100 randomly selected sub-datasets for NO emission factors. The error bars represent the $95 \%$ confidence intervals. 


\subsection{Implications}

This study shows that the instantaneous vehicle emissions are highly dynamic under real driving conditions. The two emission factors of one vehicle measured by the dual RS technique demonstrate little correlation, even under the same driving conditions when the vehicle passes by the two RS systems. This indicates that solely relying on the vehicle dynamics such as the speed and acceleration or even the site road slope is insufficient to fully characterise their emissions. A vehicle emitting low (or high) emissions when it passes by the first RS system does not necessarily guarantee that it will also emit low (or high) emissions at the second RS system. Consequently, one snapshot measurement by RS is insufficient to accurately indicate the emission level of a passing vehicle. In particular, when it comes to on-road identification of high-emitting vehicles, using a single RS system without due consideration of such real-world emission variability would result in false detections. Therefore, to increase the accuracy of high-emitters detection, a dual RS technique is developed which incorporates suitable and sufficiently high cutpoints to prevent false detections. A vehicle is considered as high-emitting only if both measurements exceed the cutpoint.

Although the two instantaneous vehicle emissions are highly variable, both single and dual RS techniques will achieve the same accuracy performance when a large number of measurements are available. Further statistical analysis shows that RS measurements will converge to a Gamma distribution when the sample size is over 200. This indicates that the uncertainties of snapshot RS measurements are cancelled out and accurate mean emission factors can be obtained from a large RS dataset. A sample size lower than 200 would result in biased emissions distribution and thus derive inaccurate mean emission factors and trends. This study suggests that a minimum of $200 \mathrm{RS}$ measurements are required to derive an accurate and reliable mean emission factor for a given sampled vehicle group (e.g. a specific vehicle class or fuel type).

\section{Conclusions}

This study investigated the emission characteristics of on-road vehicles using a unique dual RS technique. A one-year continuous measurement program was carried to collect a substantial dataset of on-road vehicle emissions. The program obtained 405096 valid pairs of emission records for 182183 unique vehicles. Statistical analysis was carried out to evaluate the characteristics of instantaneous emissions measured by the dual RS technique and the effect of sample size on emission distribution. The key findings of this study are:

1) The two emission factors measured by the dual RS technique demonstrate little correlation even when vehicle dynamics are taken into consideration, indicating that instantaneous vehicle emissions are highly dynamic under real-world driving conditions. As a result, one snapshot measurement from a single RS technique may be insufficient to accurately represent the emission level of a passing vehicle. Using a dual RS technique is recommended to increase the accuracy of identification of high-emitting vehicles. 
2) Despite the little correlation, the dual RS technique measures the same mean emission factors and trends as the conventional single RS technique. This is because the uncertainties of snapshot measurements are cancelled out when a large number of measurements are available.

3) Statistical analysis shows that both RS systems demonstrated the same Gamma distribution with 200 or more measurements, leading to converged mean emission factors for a given group of vehicles. Therefore, this study highlights that a minimum sample size of $200 \mathrm{RS}$ measurements is required to generate sufficiently accurate and repeatable mean emission factors.

4) This study suggests that using the single or dual RS technique will depend on the purpose of applications. For evaluating the average emissions of any given fleet or individual vehicle, the single and dual RS techniques have the same accuracy as long as sufficient measurements are taken. However, for identifying individual high-emitters based on only one measurement, the dual RS technique has a higher accuracy than the single RS technique.

\section{CRediT authorship contribution statement}

Yuhan Huang: Methodology, Formal analysis, Writing - original draft, Writing - review \& editing. Yang Yu: Software, Writing - review \& editing. Yat-Shing Yam: Conceptualization, Writing - review \& editing. John L. Zhou: Supervision, Writing - review \& editing. Chengwang Lei: Writing - review \& editing. Bruce Organ: Writing - review \& editing. Yuan Zhuang: Writing - review \& editing. Waichuen Mok: Writing - review \& editing. Edward F.C. Chan: Writing - review \& editing.

\section{Acknowledgement}

The authors would like to gratefully appreciate the HKEPD for providing the RS data analysed in this study. Authors acknowledge the ownership of data by HKEPD and use them with permission. The contents of this paper are solely the responsibility of the authors and do not necessarily represent official views of the Hong Kong SAR Government.

\section{Supplementary data}

Supplementary data are available online at https://doi.org/10.1016/j.envpol.2020.115456.

\section{References}

Anenberg, S.C., Miller, J., Minjares, R., et al., 2017. Impacts and mitigation of excess diesel-related NOx emissions in 11 major vehicle markets. Nature 545, 467-471.

Austin, T., Burnette, A.D., Klausmeier, R., et al., 2004. Review of Literature on Remote Sensing Devices. Eastern Research Group, Inc. 
Baum, M.M., Kiyomiya, E.S., Kumar, S., et al., 2001. Multicomponent Remote Sensing of Vehicle Exhaust by Dispersive Absorption Spectroscopy. 2. Direct On-Road Ammonia Measurements. Environ. Sci. Technol. 35, 3735-3741.

Beaton, S.P., Bishop, G.A., Zhang, Y., et al., 1995. On-Road Vehicle Emissions: Regulations, Costs, and Benefits. Science 268, 991-993.

Bishop, G.A., Haugen, M.J., 2018. The Story of Ever Diminishing Vehicle Tailpipe Emissions as Observed in the Chicago, Illinois Area. Environ. Sci. Technol. 52, 7587-7593.

Bishop, G.A., Schuchmann, B.G., Stedman, D.H., 2013. Heavy-Duty Truck Emissions in the South Coast Air Basin of California. Environ. Sci. Technol. 47, 9523-9529.

Bishop, G.A., Schuchmann, B.G., Stedman, D.H., et al., 2012. Emission Changes Resulting from the San Pedro Bay, California Ports Truck Retirement Program. Environ. Sci. Technol. 46, 551-558.

Bishop, G.A., Starkey, J.R., Ihlenfeldt, A., et al., 1989. IR Long-Path Photometry: A Remote Sensing Tool for Automobile Emissions. Anal. Chem. 61, 671A-677A.

Bishop, G.A., Stedman, D.H., Ashbaugh, L., 1996. Motor Vehicle Emissions Variability. J. Air Waste Manag. Assoc. 46, 667-675.

Bishop, G.A., Stedman, D.H., Hutton, R.B., et al., 2000. Drive-by Motor Vehicle Emissions: Immediate Feedback in Reducing Air Pollution. Environ. Sci. Technol. 34, 1110-1116.

Borken-Kleefeld, J., Chen, Y., 2015. New emission deterioration rates for gasoline cars - Results from long-term measurements. Atmos. Environ. 101, 58-64.

Burgard, D.A., Bishop, G.A., Stadtmuller, R.S., et al., 2006. Spectroscopy Applied to On-Road Mobile Source Emissions. Appl. Spectrosc. 60, 135A-148A.

Carslaw, D.C., Beevers, S.D., Tate, J.E., et al., 2011. Recent evidence concerning higher NOx emissions from passenger cars and light duty vehicles. Atmos. Environ. 45, 7053-7063.

Carslaw, D.C., Rhys-Tyler, G., 2013. New insights from comprehensive on-road measurements of NOx, NO2 and NH3 from vehicle emission remote sensing in London, UK. Atmos. Environ. 81, 339347.

Chen, Y., Borken-Kleefeld, J., 2014. Real-driving emissions from cars and light commercial vehicles Results from 13 years remote sensing at Zurich/CH. Atmos. Environ. 88, 157-164.

Chen, Y., Borken-Kleefeld, J., 2016. NOx Emissions from Diesel Passenger Cars Worsen with Age. Environ. Sci. Technol. 50, 3327-3332.

Chen, Y., Zhang, Y., Borken-Kleefeld, J., 2019. When is Enough? Minimum Sample Sizes for On-Road Measurements of Car Emissions. Environ. Sci. Technol. 53, 13284-13292.

Hanigan, I.C., Rolfe, M.I., Knibbs, L.D., et al., 2019. All-cause mortality and long-term exposure to low level air pollution in the '45 and up study' cohort, Sydney, Australia, 2006-2015. Environ. Int. 126, 762-770. 
He, H., Fan, J., Li, Y., et al., 2017. When to switch to a hybrid electric vehicle: A replacement optimisation decision. J. Clean. Prod. 148, 295-303.

HKEPD, 2020a. Phasing Out Pre-Euro IV Diesel Commercial Vehicles. http://www.epd.gov.hk/epd/english/environmentinhk/air/prob_solutions/Phasing_out_diesel_co mm_veh.html <accessed 18.02.2020>.

HKEPD, 2020b. Strengthened Emissions Control for Petrol and LPG Vehicles. https://www.epd.gov.hk/epd/english/environmentinhk/air/guide_ref/remote_sensing_Petrol_n_L $\underline{\text { PG.htm }}$ <accessed 19.05.2020>.

Huang, Y., Ng, E.C.Y., Surawski, N.C., et al., 2020a. Large eddy simulation of vehicle emissions dispersion: Implications for on-road remote sensing measurements. Environ. Pollut. 259, 113974.

Huang, Y., Ng, E.C.Y., Yam, Y.-s., et al., 2019a. Impact of potential engine malfunctions on fuel consumption and gaseous emissions of a Euro VI diesel truck. Energy Convers. Manage. 184, 521-529.

Huang, Y., Ng, E.C.Y., Zhou, J.L., et al., 2018a. Eco-driving technology for sustainable road transport: A review. Renew. Sustain. Energy Rev. 93, 596-609.

Huang, Y., Organ, B., Zhou, J.L., et al., 2018b. Remote sensing of on-road vehicle emissions: Mechanism, applications and a case study from Hong Kong. Atmos. Environ. 182, 58-74.

Huang, Y., Organ, B., Zhou, J.L., et al., 2019b. Characterisation of diesel vehicle emissions and determination of remote sensing cutpoints for diesel high-emitters. Environ. Pollut. 252, 31-38.

Huang, Y., Surawski, N.C., Organ, B., et al., 2019c. Fuel consumption and emissions performance under real driving: Comparison between hybrid and conventional vehicles. Sci. Total Environ. $659,275-282$.

Huang, Y., Surawski, N.C., Yam, Y.S., et al., 2020b. Re-evaluating effectiveness of vehicle emission control programs targeting high-emitters. Nat. Sustain. https://doi.org/10.1038/s41893-0200573-y.

Huang, Y., Yam, Y.S., Lee, C.K.C., et al., 2018c. Tackling nitric oxide emissions from dominant diesel vehicle models using on-road remote sensing technology. Environ. Pollut. 243, 1177-1185.

Lau, J., Hung, W.T., Cheung, C.S., 2012. Observation of increases in emission from modern vehicles over time in Hong Kong using remote sensing. Environ. Pollut. 163, 14-23.

Mendoza-Villafuerte, P., Suarez-Bertoa, R., Giechaskiel, B., et al., 2017. NOx, NH3, N2O and PN real driving emissions from a Euro VI heavy-duty vehicle. Impact of regulatory on-road test conditions on emissions. Sci. Total Environ. 609, 546-555.

Mera, Z., Fonseca, N., López, J.-M., et al., 2019. Analysis of the high instantaneous NOx emissions from Euro 6 diesel passenger cars under real driving conditions. Appl. Energy 242, 1074-1089.

NSW EPA, 2019. Air Emissions Inventory for the Greater Metropolitan Region in New South Wales 2013 Calendar Year. 
Organ, B., Huang, Y., Zhou, J.L., et al., 2019. A remote sensing emissions monitoring programme reduces emissions of gasoline and LPG vehicles. Environ. Res. 177, 108614.

Organ, B., Huang, Y., Zhou, J.L., et al., 2020. Simulation of engine faults and their impact on emissions and vehicle performance for a liquefied petroleum gas taxi. Sci. Total Environ. 716, 137066.

Pujadas, M., Domínguez-Sáez, A., De la Fuente, J., 2017. Real-driving emissions of circulating Spanish car fleet in 2015 using RSD Technology. Sci. Total Environ. 576, 193-209.

Ropkins, K., DeFries, T.H., Pope, F., et al., 2017. Evaluation of EDAR vehicle emissions remote sensing technology. Sci. Total Environ. 609, 1464-1474.

Sjödin, Å., 1994. On-Road Emission Performance of Late-Model TWC-Cars as Measured by Remote Sensing. Air \& Waste 44, 397-404.

Stedman, D.H., Bishop, G.A., Aldrete, P., et al., 1997. On-Road Evaluation of an Automobile Emission Test Program. Environ. Sci. Technol. 31, 927-931.

Stephens, R.D., Cadle, S.H., 1991. Remote Sensing Measurements of Carbon Monoxide Emissions from On-Road Vehicles. J. Air Waste Manag. Assoc. 41, 39-46.

WHO, 2020. Ambient air pollution - a major threat to health and climate. https://www.who.int/airpollution/ambient/en/ <accessed 26.06.2020>.

Zhang, Y., Bishop, G.A., Stedman, D.H., 1994. Automobile Emissions Are Statistically Gamma Distributed. Environ. Sci. Technol. 28, 1370-1374.

Zhao, B., Johnston, F.H., Salimi, F., et al., 2020. Short-term exposure to ambient fine particulate matter and out-of-hospital cardiac arrest: a nationwide case-crossover study in Japan. Lancet Planet. Health 4, e15-e23. 